\title{
An Express Methodology for Calculating the Reliability of Power Supply Systems with Autonomous Power Sources
}

\author{
M.S. Ershov ${ }^{1}$, V.V. Blyuk ${ }^{1 *}$, R.B. Zhalilov ${ }^{2}$ \\ ${ }^{1}$ National University of Oil and Gas "Gubkin University”, Moscow, Russia \\ ${ }^{2}$ Bukhara Engineering and Technology Institute, Bukhara, Uzbekistan
}

\begin{abstract}
Autonomous power sources are widely used in systems for power supply to industrial facilities, especially in the oil and gas industries that have affordable energy carriers. These sources can be used both separately and in combination with centralized power supply, as primary, backup, or emergency sources. Their operation is characterized by the features that affect power supply reliability and must be taken into account when deciding on their use in the stages of designing new power supply systems or modernizing existing ones. The use of methodology and software for calculating the reliability of systems with autonomous power sources in the stage of pre-project research can contribute to more informed decision-making. In this stage, there is no need and opportunity to consider all reliability issues in detail. Here, express methods are enough to take into account the main features of the systems functioning with autonomous or mixed power sources and to compare the proposed system options within a single methodological framework. Based on this, a methodology was developed to calculate the reliability of power supply systems with autonomous and mixed power sources. The proposed methodology employs semiMarkov random processes (Markov chains) and can be used in comparative reliability analysis of power supply options with autonomous and mixed power sources. It was implemented in software and is accompanied by an example of reliability calculation for power supply to a stationary platform for maintaining reservoir pressure in an offshore oil field.
\end{abstract}

Keywords: reliability, methodology, random processes, power supply system, autonomous sources.

\footnotetext{
${ }^{*}$ Corresponding author.

E-mail: blyuk.v@gubkin.ru
}

http://dx.doi.org/10.38028/esr.2020.02.0002

Received March 06, 2020. Revised April 11, 2020.

Accepted July 03, 2020. Available online October 21, 2020.

This is an open access article under a Creative Commons Attribution-NonCommercial 4.0 International License.

(C) 2020 ESI SB RAS and authors. All rights reserved.

\section{INTRODUCTION}

Oil and gas production, transportation, and processing facilities characterized by complex continuous processes require a highly reliable power supply. Along with centralized energy sources, autonomous auxiliary power plants based on diesel or gas turbine plants have long been used to power consumers in the oil and gas industry. Depending on the number and type of power sources used, the conditions for their parallel operation with centralized power sources, and constraints on the allowable time for power supply interruption, there can be various types of power supply systems with autonomous power sources in terms of reliability. The reliability assessment in the stage of pre-design surveys and the development of technical specifications for design facilitate the identification of the most rational power supply options in an early stage. In this stage, when the equipment has not yet been selected, it is impossible and unnecessary to consider in detail the reliability of all system elements. It is sufficient to take into account the reliability of the main elements (power sources), the availability of structural and time redundancy, the reliability of automatic systems that ensure the connection of backup and emergency power sources, and the repair restrictions.

This study aims to develop an express methodology for calculating the reliability of industrial power supply systems with autonomous and mixed (centralized and offgrid) power sources.

\section{SELECTION OF A RELIABILITY CALCULATION PARAMETER}

The method underlying the methodology for reliability calculation was selected given the above features of the operation of power supply systems related to restored and redundant systems, as well as constraints on information support of initial data when identifying power supply options in the stage of designing new systems or modernizing existing ones. The selection of the method involved analysis of the methods of the theory of reliability of engineering and electric power systems [1-9], and their application [10-20], including modeling the reliability of power supply systems for oil and gas production [18-22]. 
As a result, the methodology is based on the method of mathematical modeling of semi-Markov random processes $[7,8,12,13,16]$. This allows factoring in the presence of structural and time redundancy, the reliability of automatic systems that provide the connection of backup and emergency power sources, constraints on repairs of power supply systems, determining stationary reliability indices, and, if necessary, investigating their changes over time.

The specific feature of the proposed methodology lies in the generalization of experience in modeling the reliability of power supply systems $[12,14,16,17,19,20,21]$, the possibility of obtaining a fairly complete set of reliability indices, determining the recoverability of the systems and their differentiation by integral reliability index, i.e., the amount of power undersupply based on the mathematical tool of semi-Markov random processes.

\section{THE METHODOLOGY FOR MODELING AND CALCULATING POWER SUPPLY SYSTEM RELIABILITY}

The methodology includes the following steps $[5,6,12$, 20, 21]:

- formation of space and state graph of the system;

- mathematical description of the space and state graph of the system;

- determination of the system reliability indices

\section{A. The formation of space and state graph of the system}

This stage suggests taking into account working, standby, and repair states of power sources and system tie lines, i.e., power lines that include 6 (10) $\mathrm{kV}$ switchgears of technological plants to which generators of autonomous power sources are connected. Along with structural redundancy characterized by backup generating capacities and tie lines, there is also a time reserve in power supply systems $[5,17]$, which implies that consumers allow a short break in the power supply. The interruption in power supply during the operation of the automatic load transfer (ALT) switch does not stop the process and is not considered a failure. Along with the failures of elements (sources, lines) and failures in switching to a backup source, one should take into account the possibility of system failures, which can be caused by interruptions in fuel supply to generating electric units and the failure of relay protection of power supply systems.

Failures of system elements occur with intensity $\lambda_{i} 1 / \mathrm{yr}$; the recovery intensity $\mu_{i}$ is $1 / \mathrm{yr},(i=1, \ldots, n)$. Here $n$ is the number of basic system elements (sources and lines). The intensity of their failure and recovery is inverse to the average time between failures and average recovery time, respectively.

The possibility of an unsuccessful ALT is characterized by probability $q_{A} \mathrm{LT}$. The probability of a successful ALT is $1-q_{A}$ LT. It allows taking into account the probability $q^{\prime}$ of failure of the automatic device and the probability $q^{\prime \prime}$ that the connection time $\tau$ will exceed the allowable time $t^{*}$, as well as the presence of technological (functional) reserve $\delta$ (takes value 1 with technological reserve, and value $0-$ without it) [18]. Determining the permissible time of interruption in the power supply to facilities, one should use corporate standards, for example, [23], for PJSC Gazprom. In the absence of a technological reserve, the probability of ALT failure is determined by the sum of probabilities of two events: the automatic devices fail or the connection time of the backup source exceeds the permissible time in case of failure of automati c device $q_{A} \mathrm{LT}=q^{\prime}+\left(1-q^{\prime}\right) q^{\prime \prime}$. The probability $q^{\prime \prime}$ is determined by the laws of distribution of the connection time $F(t)$ and the permissible time of power outage $D(t)$. The distribution of the random variable is in good agreement with the biased exponential law

$$
F(t)=\left\{\begin{array}{c}
0, t \leq b \\
1-e^{-\frac{t-b}{a}}, t>b^{\prime}
\end{array}\right.
$$

where is the minimum load connection time; is a statistical parameter. The degenerate distribution law corresponds to a fixed value of the permissible time of power outage

$$
D(t)=\left\{\begin{array}{l}
0, t \leq t^{*} \\
1, t>t^{*}
\end{array}\right.
$$

The probability that the connection time exceeds the permissible time is

$q^{\prime \prime}=P\left\{\tau \geq t^{*}\right\}=\int_{0}^{\infty} D(t) * d F(t)=\left\{\begin{array}{c}0, t \leq b \\ 1-e^{-\frac{t-b}{a}}, t>b\end{array}\right.$

The probabilities of events allow "sifting" the flow of failures and recoveries $[17,18,20]$. In case of unsuccessful ALT, a generating unit or a system tie line is connected manually by the operator. The power plant unit is put into operation manually with intensity $\mu_{m e}$. Manual connection of tie line or sectional switch is carried out with intensity $\mu_{m s}$.

System failures are characterized by the intensity of full failures $\lambda_{s}$ or the intensity of partialfailures $\lambda_{s s}$ and recoveries $\mu_{s}$ or $\mu_{s s}$, respectively. The rates of system failures associated with the probability $q_{r p}$ of failure of relay protection are determined by the product of the failure rate in the electrical network of the system $\lambda_{e n}$ and the specified probability.

The state and transition graph is formed based on the analysis of possible states and includes a finite set of states $X=\left\{x_{1}, x_{2}, x_{3}, \ldots, x_{n}\right\}$, which is divided into subsets of operable states $X_{u s}$ and inoperable states $X_{d s}$. The formation of states should take into account the main states and neglect the secondary ones. It is assumed that the combination of independent failures of more than three main system elements is impossible [2, 3]. A subset of inoperable states is divided into several levels, ranked by power shortage in the system.

$B$. The mathematical description of the space and state graph of the system

Initially, the process is described by the intensity matrix of the system transitions from one state to another. Based on the intensity matrix, the vector of the average residence 
time of the system in the states and the transition probability matrix between the states are determined. Element of a vector of average residence time in a state is defined as reciprocal of the sum of intensities of transitions leaving this state. Element of the transition probability matrix is defined as the ratio of the intensity of transition from state to state to the sum of the intensities of all transitions leaving state .

Based on the original matrix, vector of stationary probabilities of the process is found. Stationary probabilities are found from the system of equations $[5,18]$

$$
\pi_{i}=\sum_{i, j}^{n} p_{i j} \pi_{j}
$$

and normalization conditions

$$
\sum_{i=1}^{n} \pi_{i}=1
$$

The Gauss method is used to solve the system of equations.

\section{Determination of system reliability indices}

The calculation of the power supply reliability is reduced to the determination of reliability indices. A set of reliability indices includes:

$T_{H}, g$ is mean operating time to failures;

$T_{B}, h$ is mean time to restoration;

$A_{F}$ is an availability factor;

$F, 1 /$ yr is an average failure rate;

$\Delta W, \mathrm{kWh} / \mathrm{yr}$ is an average annual power undersupply.

The mean operating time to failures of the system $T_{H}$ is defined as the average time during which process was in a subset of operable $X_{u s}$. The expression $T_{H}$ is used to calculate

$$
T_{H}=\frac{\sum \pi_{k} a_{k}}{\sum \pi_{k} \sum p_{k l}}, \quad\left(x_{k} \in X_{u s}, x_{l} \in X_{d s}\right),
$$

where $x_{k}$ is operable; $x_{1}$ is inoperable.

The average recovery time is defined as the average time during which the process was in a subset of inoperable $X_{d s}$. The expression $T_{B}$ is used to calculate

$$
T_{B}=\frac{\sum \pi_{l} a_{l}}{\sum \pi_{l} \sum p_{l k}}, \quad\left(x_{k} \in X_{u s}, x_{l} \in X_{d s}\right)
$$

The system availability factor is defined as the

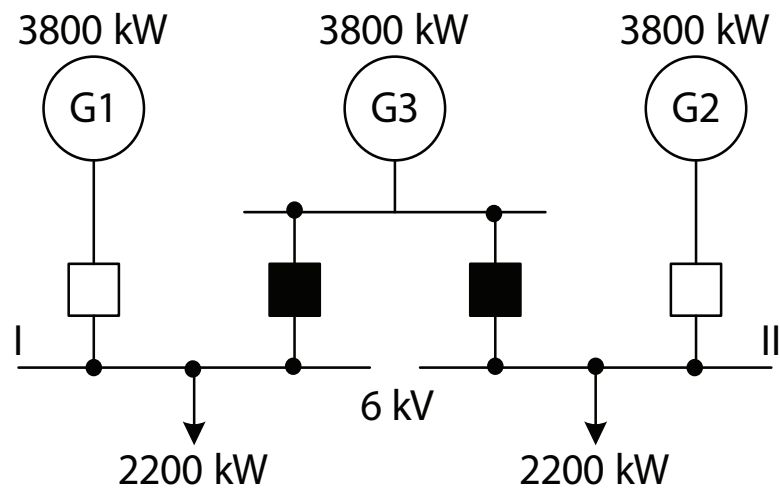

Fig. 1. Scheme of the power plant of the reservoir pressure maintenance platform.

stationary probability of a process staying in a subset of operable states. The expression is used to calculate

$$
A_{F}=\frac{T_{H}}{T_{H}+T_{B}}=\frac{\sum \pi_{k} a_{k}}{\sum \pi_{k} a_{k}+\sum \pi_{l} a_{l}}
$$

The average system failure rate is determined from the ratio

$F_{i}=\frac{A_{F}}{T_{H}}=\frac{\sum \pi_{k} \sum p_{k l}}{\sum \pi_{k} a_{k}+\sum \pi_{1} a_{1}}, \quad\left(x_{k} \in X_{u s}, x_{l} \in X_{d s}\right)$

The indices determined by formulas (6) - (9) can be differentiated by the levels of power shortage in inoperable states.

The average annual power undersupply at the i-th level of power shortage in power supply systems is estimated based on the calculated reliability indices according to the formula

$$
\Delta W_{i}=\Delta P_{i} \cdot F_{i} \cdot T_{B i},
$$

where is the power shortage level, $\mathrm{kW}$; is a failure rate leading to this level of power shortage, $1 / \mathrm{yr}$; is the average recovery time after failure with a given level of power shortage, $h$. Power shortage is determined by analyzing inoperable states as the difference between the power of consumers and the available generated power, and if there are system tie lines to other power plants, their transfer capability is taken into account.

\begin{tabular}{|c|c|c|c|c|c|}
\hline \multirow{2}{*}{ No. ofstates } & \multicolumn{4}{|c|}{ The number of units } & \multirow{2}{*}{$\begin{array}{c}\text { Power shortage } \\
\text { KW }\end{array}$} \\
\hline & In operation & On standby & Under repair & Pending repair & \\
\hline 1 & 2 & 1 & 0 & 0 & 0 \\
\hline 2 & 2 & 0 & 1 & 0 & 0 \\
\hline 3 & 1 & 1 & 0 & 1 & 600 \\
\hline 4 & 1 & 1 & 1 & 1 & 600 \\
\hline 5 & 0 & 0 & 1 & 2 & 4400 \\
\hline 6 & 0 & 0 & $1, \mathrm{~S}$ & 1 & 4400 \\
\hline 7 & 0 & 0 & $\mathrm{~S}$ & 0 & 4400 \\
\hline 8 & 0 & 0 & $1, \mathrm{~S}$ & 0 & 4400 \\
\hline
\end{tabular}

During scheduled preventive repairs (SPR) of the main system elements, i.e., units of power plants and system tie lines, the redundancy of the system decreases, which reduces its reliability during a specified period. The evolution of the

Table 1.Identification of states of the power supply system of the rpm platform under normal operating conditions.

Note: $\mathrm{S}$ is system failure. 
Table 2. Identification of the states of the power supply system of the rpm platform under the scheduled repair conditions.

\begin{tabular}{|c|c|c|c|c|c|}
\hline \multirow[b]{2}{*}{ No. of states } & \multicolumn{4}{|c|}{ THE NUMBER OF UNITS } & \multirow[b]{2}{*}{ Power shortage $\mathrm{kW}$} \\
\hline & In operation & On standby & Under repair & Pending repair & \\
\hline 1 & 2 & 0 & SPR, 0 & 0 & 0 \\
\hline 2 & 1 & 0 & SPR, 1 & 0 & 600 \\
\hline 3 & 0 & 0 & SPR, 1 & 1 & 4400 \\
\hline 4 & 0 & 0 & $\mathrm{SPR}, 1, \mathrm{~S}$ & 0 & 4400 \\
\hline 5 & 0 & 0 & SPR, S & 0 & 4400 \\
\hline
\end{tabular}

Note: SPR is a scheduled preventive repair of the unit

system during SPR corresponds to its graph of states and transitions, which allows calculating the reliability indices of the system in the corresponding period. The resulting system reliability indices are calculated as a weighted average, given the value of the corresponding index and the duration of the system operation throughout the year under normal and repair conditions.

Reliability calculation algorithms are implemented in the reliability program, which was used in calculations for the example below.

\section{AN EXAMPLE OF CALCULATING THE RELIABILITY} INDICES OF THE POWER SUPPLY SYSTEM OF THE PLATFORM FOR MAINTAINING THE RESERVOIR PRESSURE OF AN OFFSHORE OIL FIELD

The power plant of the reservoir pressure maintenance (RPM) platform, shown in Figure 1, includes three units with a rated power of $3800 \mathrm{~kW}$ each; there are no system connections with power plants of other facilities of the field. Under normal operating conditions, two units loaded at $57.9 \%$ work at separate busbar sections, the third unit is on standby.
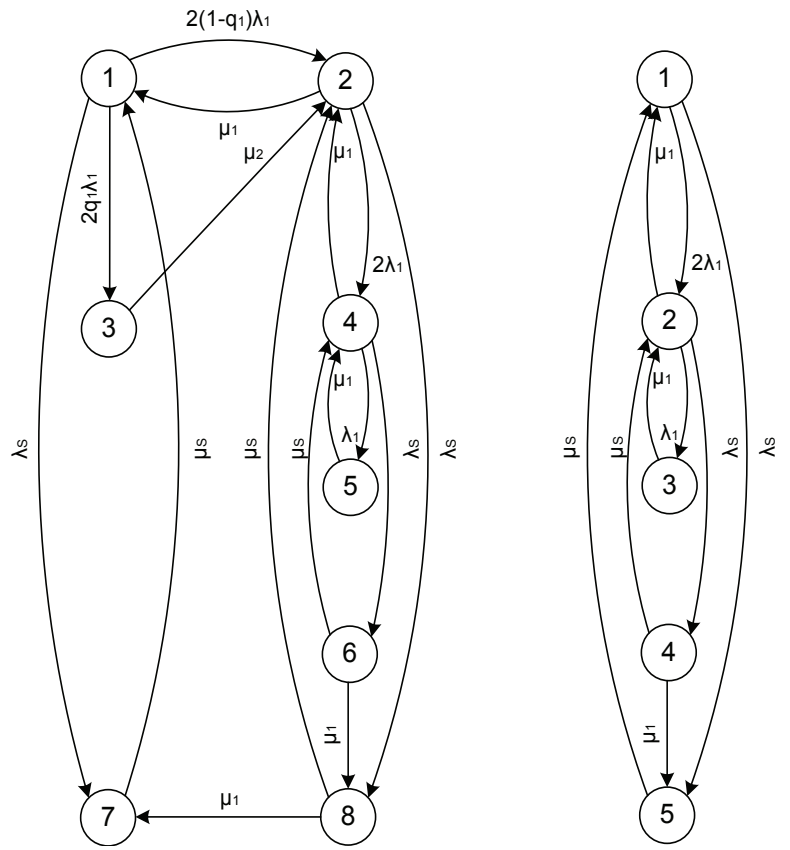

Fig. 2. The state graph of the power supply system of the RPM platform: a) under normal conditions; b) under repair conditions.
Title: RPM-SR-4400

Power shortage: $4400 \mathrm{~kW}$ Input Data:

$$
\begin{aligned}
& \mathrm{L}(1)=6 \mathrm{M}(1)=175 \quad \mathrm{Q}(1)=0.12 \\
& \mathrm{~L}(3)=1 \mathrm{M}(2)=8760 \quad \mathrm{Q}(2)=0.88 \\
& M(3)=8760
\end{aligned}
$$

Inefficient states: 5678

The specification statement of the graph:

$$
\begin{aligned}
& \mathrm{P}(1.2)={ }^{*} \mathrm{Q} 2{ }^{*} \mathrm{~L} 1 \mathrm{P}(2.1)=\mathrm{M} 1 \quad \mathrm{P}(3.2)=\mathrm{M} 2 \\
& P(1.3)=2{ }^{*} \mathrm{Q} 1^{\star} \mathrm{L} 1 \quad \mathrm{P}(2.4)=2{ }^{*} \mathrm{~L} 1 \\
& P(2.8)=L 3 \\
& P(4.2)=M 1 \quad P(5.4)=M 1 \quad P(6.4)=M 3 \\
& P(4.5)=L 1 \quad P(6.8)=M 1 \\
& P(4.6)=L 3 \\
& P(7.1)=M 3 \quad P(8.2)=M 3 \\
& P(8.7)=M 1
\end{aligned}
$$

Transition probability matrix:

$$
\begin{array}{ll}
\mathrm{P}(1.2)=0.88 & \mathrm{P}(2.1)=0.93085 \\
\mathrm{P}(4.2)=0.96154 & \mathrm{P}(5.4)=1 \mathrm{P}(6.4)=0.98041 \\
\mathrm{P}(4.5)=0.03297 & \mathrm{P}(6.8)=0.01959 \\
\mathrm{P}(7.1)=1 & \mathrm{P}(8.2)=0.98041 \\
& \mathrm{P}(8.7)=0.01959
\end{array}
$$

Average time of stay in Vector of probability of final states:

state Xi (yr):

$$
\begin{array}{ll}
A[1]=0.08333 & \Pi[1]=0.439746 \\
A[2]=0.00532 & \Pi[2]=0.47236 \\
A[3]=0.00011 & \Pi[3]=0.05277 \\
A[4]=0.00549 & \Pi[4]=0.031353 \\
A[5]=0.00571 & \Pi[5]=0.001034 \\
A[6]=0.00011 & \Pi[6]=0.000172 \\
A[7]=0.00011 & \Pi[7]=4.9 \mathrm{E}-5 \\
A[8]=0.00011 & \Pi[8]=0.002516
\end{array}
$$

Reliability parameters:

Time between failures $\mathrm{TH}=15.58 \mathrm{yr}$ Average time of recovery $T B=21.63 \mathrm{hr}$ Availability factor $A F=0.9998$ Average failure rate $\mathrm{F}=0.0641 / \mathrm{yr}$ Expected power shortage $\Delta \mathrm{W}=6106 \mathrm{~kW}{ }^{*} \mathrm{hr} / \mathrm{yr}$

Fig. 3. A fragment of an output report of the program for calculating system reliability under normal conditions. 
Table 3. The calculated system reliability indices.

\begin{tabular}{|c|c|c|c|}
\hline 1 & 2 & 3 & \\
\hline \multirow{3}{*}{ Indices } & \multicolumn{3}{|c|}{ Conditions } \\
\hline & \multicolumn{3}{|c|}{$\begin{array}{l}\text { Power shortage under normal operating } \\
\text { conditions, } \mathrm{kW}\end{array}$} \\
\hline & 600 & 4400 & $600-4400$ \\
\hline$\overline{T_{H}, \mathrm{~g}}$ & 0.47 & 15.58 & 0.46 \\
\hline$T_{B}, \mathrm{~h}$ & 18.83 & 21.63 & 18.92 \\
\hline \multirow{2}{*}{$F \quad 1 / \sigma{ }^{A F}$} & 0.9955 & 0.9998 & 0.9953 \\
\hline & 2.108 & 0.064 & 2.172 \\
\hline$\Delta W \mathrm{k} . \mathrm{Wh} / \mathrm{g}$ & 23821 & 6106 & 29927 \\
\hline
\end{tabular}

\begin{tabular}{|c|c|c|c|}
\hline 5 & 6 & 7 & 8 \\
\hline \multicolumn{3}{|c|}{ Conditions } & \multirow{3}{*}{$\begin{array}{c}\text { Total values } \\
\text { with a shortage } \\
\text { of } 600-4400\end{array}$} \\
\hline \multicolumn{3}{|c|}{$\begin{array}{l}\text { Power shortage under scheduled repair of the } \\
\text { unit, } \mathrm{kW}\end{array}$} & \\
\hline 600 & 4400 & $600-4400$ & \\
\hline 0,08 & 1.00 & 0.08 & 0.45 \\
\hline 50,05 & 21.63 & 47.86 & 19.91 \\
\hline 0,9358 & 0.9975 & 0.9337 & 0.9932 \\
\hline 11,230 & 0.997 & 12.13 & 2.513 \\
\hline 337269 & 94927 & 432196 & 43705 \\
\hline
\end{tabular}

Thus, under normal operating conditions, the power of a power plant is distributed as follows:

- power consumption (including losses) is calculated as

follows: $2 \cdot 3800 \cdot 0,579 \approx 4400 \mathrm{~kW}$;

- generated power is $4400 \mathrm{~kW}$;

- hot reserve of generating capacity is $3200 \mathrm{~kW}$;

- cold reserve of generating capacity is $3800 \mathrm{~kW}$.

In case of a failure of a power plant unit, it is switched off, and a standby unit is automatically switched on. The failure rate of all power plant units is the same and equals $\lambda_{1}$. The operational state of failed units is restored with intensity $\mu_{1}$, according to a limited successive repair strategy, i.e., only one unit is under repair at a time, the subsequently failed unit is repaired after the repair of a unit that failed earlier.

With successful automatic load transfer, the load is not disconnected, or the disconnection is too short to affect the production process and can be ignored. If ALT fails, part of the load is disconnected. Then, the backup unit can be put into operation by operational personnel manually with intensity $\mu_{2}$. Unsuccessful ALT is characterized by probability $q_{1}$, successful one - by probability $q_{2}=\left(1-q_{1}\right)$. In the process, the failure rate can be $\lambda_{s}$. The system recovers from failures with intensity $\mu_{S}$.

For the power supply system to the RPM platform under consideration, the values of the initial parameters are: $\lambda_{1}=6(1 / \mathrm{yr}) ; \lambda_{S}=1(1 / \mathrm{yr}) ; \mu_{1}=175(1 / \mathrm{yr}) ; \mu_{S}=8760(1 /$ $\mathrm{yr}) ; \mu_{2}=8760(1 / \mathrm{yr}) ; q_{1}=0.12$. The values of the initial data are determined from the operation data of the considered facility.
Figure 2 shows the graph of states and transitions of the power supply system of the RPM platform under normal operating and preventive repair conditions.

Figure 3 presents a fragment of intermediate calculations and calculation results for the system under normal operating conditions. Table 3 indicates the results of modeling the considered system reliability for standard and repair conditions differentiated by power shortage.

The findings indicate that with limited structural redundancy, which normally meets the "N-1" criterion (the failure-free operation is ensured if one of the existing generating units fails), during the period of scheduled repairs, the reliability indices of the system significantly decrease, which results in almost a 1.5 -fold increase in the average annual power undersupply. Therefore, alternative solutions for this system can be the installation of an additional generator or additional system tie line, i.e., a cable transmission line connecting the RPM platform with a neighboring technological platform with off-grid power sources that have surplus generating capacity. In this case, the "N-1" criterion is met under repair conditions and the "N-2" criterion is met under normal operation of the system. One more cable line is much cheaper than an additional generator because it does not require extra space, which is crucial due to insufficient space on sea platforms. Moreover, with backup power sources, it provides a faster and more reliable load transfer and reduces the probability of failure when switching to a backup power source. Modeling the reliability of a system with an additional system tie line, given the reduction in the failure probability when switching from the main power source to an emergency one, has been shown twice.

\section{CONCLUSION}

The proposed method for calculating the reliability of power supply systems with off-grid power sources is developed based on analysis of power supply to oil and gas industry facilities and methods for ensuring an appropriate selection of power supply sources of industrial systems when designed and reconstructed. The development of our method involved semi-Markov random processes (Markov chains), which allows an express reliability assessment of systems with off-grid power sources.

\section{REFERENCES}

[1] Yu.N. Rudenko, M.B. Cheltsov "Reliability and redundancy in power systems," Novosibirsk, Russia: Nauka, 1974, p. 263.

[2] Reliability of technical systems, Ed. I.A. Ushakova. Radio and communications, Moscow, Russia, 1985.

[3] Reliability of energy systems and their equipment, vol. 4, T. 2, Reliability of electric power systems/ ed. by M.N. Rudenko. Energoatomizdat, Moscow, Russia, 2000.

[4] A.M. Polovko S.V. Gurov "Fundamentals of reliability theory," 2nd ed., Saint Petersburg, Russia: $B H V$ Petersburg, 2006. 
[5] B.P. Kredenter "Prediction of the reliability of systems with temporary redundancy", Kyiv, Ukraine: Naukova Dumka, 1988.

[6] Roy Billinton, Ronald N. Allan "Reliability evaluation of engineering systems: Concepts and Techniques," 2nd ed. New York, London: Plenum Press, 1992, p. 509.

[7] Limnios N., Oprisan G. Semi-Markov Processes and Reliability. -New York: Springer Science + Business Media, LLC, 2001. - p. 222.

[8] Wai-Ri Ching, Michael K. Ng Markov Chains: Models, Algorithms, and Application. - New York: Springer Science + Business Media, Inc, 2006. - p. 211.

[9] A.S. Vanin, Yu.A. Fokin "Decomposition approach to the calculation of reliability indicators of power supply systems" Methodological issues of research on the reliability of large energy systems. Reliability of energy systems: achievements, problems, prospects. ESI SB RAS, vol. 64. 2014, pp. 417-426.

[10] O.V. Svezhentseva, N.I. Voropay "Optimization of the placement of power supplies in the formation of a rational configuration of the power supply system." Electricity, vol.10, 2012, pp. 7-14.

[11] P. Wang, R. Billinton, "Reliability cost/worth assessment of distribution systems incorporating time-varying weather conditions and restoration resources." IEEE Trans on Power Delivery, vol. 17, no. 1, 2002, pp. 260265.

[12] Ricky W. Butler, Sally C. Johnson "Techniques for Modeling the Reliability of Fault-Tolerant Systems with the Markov State-Space Approach," NASA Reference Publication 1348/ Langley Research Center. Hampton, Virginia, USA, 1995, p. 125.

[13] Antonio Pievatolo, Enrico Tironi, and Ivan Valade Semi-Markov Processes for Power System Reliability Assessment With Application to Uninterruptible Power Supply/ IEEE Transactions on Power Systems, Vol. 19, No 3, August 2004, pp. 1326-1333.

[14] Vijayalaxmy Dharwad, S.B. Karjagi "Modeling and Analysis of RBTS IEEE-6 BUS System Based on Markov Chain," International Journal of Engineering Research and General Science, vol. 3, issue 2, part 2, 2015, pp. 686-696.

[15] Pedram Jahangiri, Mahmud Fotuhi-Firuzabad "Reliability Assessment of Distribution System with Distributed Generation," 2nd IEEE International Conference on Power and Energy (PECon 08), 2008, Johor Baharu, Malaysia, pp. 1551-1556.

[16] Knopik L, Migawa K. "Semi-Markov system model for minimal repair maintenance". Eksploatacja $i$ Niezawodnosc - Maintenance and Reliability, vol.21, no. 2, 2019 pp. 256-260, http://dx.doi.org/10.17531/ ein.2019.2.9.

[17] M.G. Sukharev, M.S. Ershov "A model of a reliable duplicated system," Reliability and quality control, no. 3, 1985, pp. 18-22.

[18] B.G. Menshov, M.S. Ershov "Reliability of power supply systems of compressor stations," Moscow, Russia: Nedra, 1995.
[19] I.V. Belousko, M.S. Ershov, A.P. Kovalev, O.A Shevchenko "On the calculation of the reliability of power supply systems for gas complexes." Electricity, no. 3, 2004, pp. 22-27.

[20] M.S. Ershov, Zyong Hoang Hai "The methodology for calculating the reliability of SES complexes of stationary offshore oil production platforms," Automation, Remote Control and Communication in the Oil Industry, no. 9, 2006, pp. 35-38.

[21] M.S. Ershov., R.B. Zhalilov "Reliability modeling of power supply systems with autonomous power sources. Methodological and practical problems of the reliability of energy systems". Book no. 1, Irkutsk, Russia: ISEM SB RAS, 2019, pp. 353-361.

[22] A.V. Turysheva, S.V. Baburin. "Justification of Power Supply System's Structure of Oil and Gas Facilities Using Backup Energy Sources with Associated Petroleum Gas as the Energy Carrier" International Journal of Applied Engineering Research ISSN 0973-4562 vol.11, no. 1, Research India Publications, 2016, pp. 749-755.

[23] STO Gazprom 2-6. 2-1028-2015. Category electrical equipment of industrial objects of OJSC "Gazprom»/ Approved and put into effect by the order of PJSC Gazprom No. 366 dated February 1, 2016.

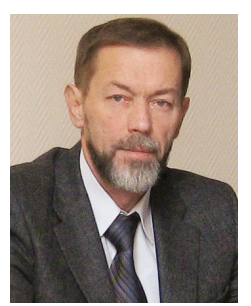

Mikhail S. Ershov

Professor, Grand Ph.D. in Engineering. Department of Electrical Engineering at the National University of Oil and Gas "Gubkin University".

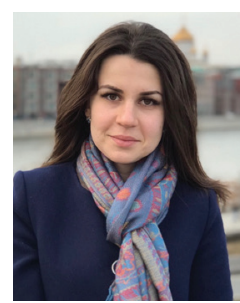

\section{Valentina V. Blyuk}

Assistant, Department of Electrical Engineering at the National University of Oil and Gas "Gubkin University".

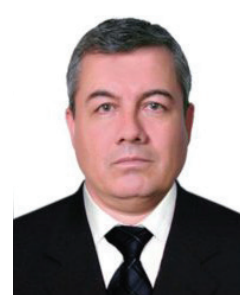

Rashid B. Zhalilov

Senior Lecturer, Ph.D. in Engineering. Bukhara Engineering and Technology Institute 